\title{
A estratégia de marcas próprias influencia a gestão da cadeia de suprimentos? Insights para o setor atacadista brasileiro
}

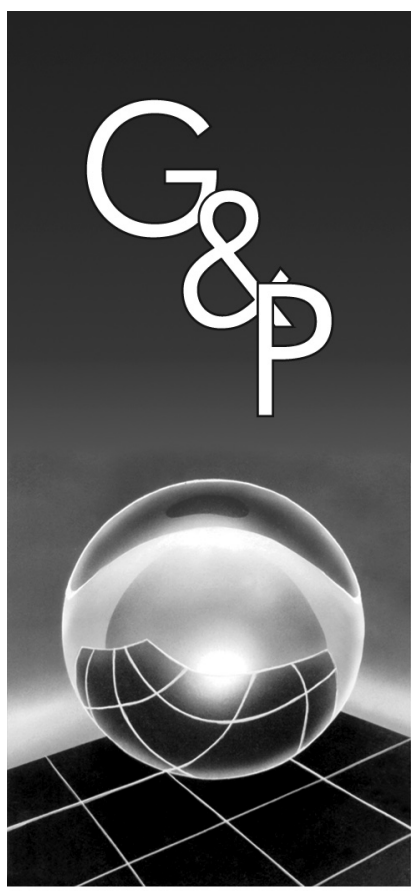

\author{
Éderson Luiz Piato \\ Andrea Lago da Silva \\ Verônica Angélica Freitas de Paula
}

Resumo

A evolução do setor atacadista nos últimos anos possibilitou que estratégias mercadológicas influenciassem significativamente suas funções empresariais tradicionais da cadeia de suprimentos. Percebe-se, na literatura, forte relação entre a estratégia de marcas próprias e as atividades da gestão de suprimentos (em especial, compras), uma vez que o desenvolvimento de marcas próprias transforma o atacadista em comprador criterioso que procura selecionar e avaliar os fornecedores (fonte de suprimento), para obter o melhor desempenho dos produtos que carregam sua marca. Nesse sentido, o principal objetivo deste artigo é analisar o impacto da estratégia de marcas próprias do atacado na atividade de gestão de suprimentos (compras), apresentando e discutindo especificamente o processo de seleção e avaliação dos fornecedores (fabricantes). A partir de um estudo multicaso com três atacadistas e duas indústrias fornecedoras, foi possível demonstrar as principais características do processo de seleção e avaliação dos fornecedores de marcas próprias.

Palavras-chave: Gestão de suprimentos. Marca própria. Atacado.

\section{Introdução}

Do ponto de vista da gestão da cadeia de suprimentos, as empresas buscam alinhar a estratégia de compras à estratégia empresarial (BAILY et al., 2000; CZINKOTA et al., 2001). Esse alinhamento tem sido mais intensamente analisado na relação entre fornecedor de materiais e empresas manufatureiras (BAILY et al., 2000), isto é, em atividades de aquisição de materiais para transformação, nas quais baseia-se grande parte das proposições conceituais em gestão de suprimentos. Entretanto, em empresas comerciais, caracterizadas pela ausência de processo de produção-transformação, o exercício da função suprimentos é uma atividade essencial para garantir giro de mercadorias (Van WEELE, 2005) e oferecer produtos no tempo certo e ao menor custo total (ALVES, 2001).

Organizações não manufatureiras - como o atacado tradicional, que se dedica a comprar, assumir propriedade, armazenar (em geral) e manusear produtos em quantidades grandes para, em seguida, revendê-los em quantidades menores - também necessitam capacitar-se no desempenho da função suprimentos. A gestão de suprimentos é aspecto muito importante para o atacado que revende produtos, pois a decisão tomada sobre "o que comprar", recai imediatamente sobre "o que vender" (BAILY et al., 2000). Contudo, a função suprimentos nas empresas comerciais está além da simples compra de produtos (Van WEELE, 2005). Atualmente, as empresas não produtoras estão mais cientes dos conceitos e técnicas de gestão de suprimentos, os quais não se restringem apenas ao processo de negociação com fornecedores.

As mudanças ocorridas no setor atacadista nos últimos anos, consequiência principalmente de sua reestruturação, e a maior integração deste agente na cadeia de suprimentos melhoraram e tornaram mais confiáveis os serviços e as relações com fornecedores e clientes. Isso pôde ser observado por meio da adoção de tecnologias avançadas e processos que aceleraram as trocas de informações, tais como EDI (eletronic data interchange), técnicas de JIT (just-in-time), QR (quick-response), CR (continuous replenishment) entre outras ferramentas (ALCÂNTARA, 1997; COUGHLAN et al., 2002).

A reestruturação do setor atacadista mundial evidenciou nova postura estratégica das empresas (LUSCH 
et al., 1993; KOTLER; KELLER, 2006). Com destaque, o atacado passou a se envolver mais com questões mercadológicas, voltadas principalmente para estratégias de diferenciação pelo desenvolvimento de marcas (ALCÂNTARA, 1997; NEVES, 1999). Seguindo a tendência mundial dos canais de distribuição da Europa e Estados Unidos, o atacado brasileiro também descobriu a importância estratégica da utilização de marcas próprias (PIATO, 2006). São chamadas marcas próprias as "marcas desenvolvidas e vendidas com exclusividade por varejistas ou atacadistas" (PARENTE, 2000, p. 194).

A estratégia de marca própria exige do atacadista maior aproximação à dinâmica do processo produtivo e, conseqüentemente, maior capacitação para a gestão de suprimentos (compras), tratada, então, como função estratégica. Desta forma, pode ser um equívoco imaginar que "comprar", para o atacadista, seja simplesmente uma questão de negociação com os fornecedores dos muitos produtos de que este agente de distribuição dispõe (Van WEELE, 2005). No caso das marcas próprias, o monitoramento dos processos produtivos, controle de qualidade e custos dos produtos, estabelecimentos de preços, prazos, contratos entre outros fatores (MARTINS, 1999; ALVES, 2001; BALLOU, 2001; DANTAS et al., 2002), são atividades imperativas para gestão de suprimentos que os atacadistas ponderam durante o processo de seleção e avaliação de seus fornecedores (fontes de suprimentos). Nesse sentido, o principal objetivo deste artigo é analisar, por meio de um estudo multicaso, a influência e o impacto da estratégia de marcas próprias do atacado na gestão de suprimentos (compras), apresentando e discutindo especificamente o processo de seleção e avaliação dos fornecedores dos produtos que terão a marca de propriedade do atacadista.

Apesar de se muito discutir a importância das marcas próprias, com destaque para os trabalhos realizados no setor varejista (McGOLDRICK, 1990; HOCH; BANERJI, 1993; SOUZA; NEMER, 1993; SHOCKER et al., 1994; BERMAN, 1996; HOCH, 1996; DHAR; HOCH, 1997; DAVIES, 1998; TAVARES, 1998; ROCHA; CHRISTENSEN, 1999; BURT, 2000; CHURCHILL; PETER, 2000; PARENTE, 2000; DHAR et al., 2001; BALTAS, 2003; MORTON; ZETTELMEYER, 2004; STEINER, 2004; VELOSO, 2004; VELOUTSOU et al., 2004; CONN, 2005; McGOLDRICK, 2005; OLIVEIRA, 2005; KOTLER; KELLER, 2006) e sob a perspectiva dos fabricantes de marcas próprias (TOILLIER, 2003), ainda pouca atenção acadêmico-científica foi dada à compreensão dos impactos proporcionados por essa estratégia no atacado, em especial, nas funções que integram sua cadeia de suprimentos. A falta desta compreensão limita as discussões científicas sobre esta estratégia no âmbito de gestão da cadeia de suprimentos. Além disso, a inexistência de trabalhos que contemplem ao mesmo tempo as literaturas de marketing e de gestão de suprimentos também motiva a realização desta análise.

O artigo está organizado da seguinte forma: inicialmente é apresentada breve revisão da literatura sobre a estratégia de marcas próprias, gestão de suprimentos (compras) e o processo de seleção e avaliação de fornecedores. Em seguida, é apresentada a metodologia adotada no estudo. Na seqüência, são apresentados os resultados do estudo multicaso realizado com três atacadistas brasileiros e duas indústrias fornecedoras. Por fim, são apresentadas as considerações finais, além de sugestões para pesquisas futuras.

\section{Revisão teórica}

A revisão teórica aborda os principais conceitos e características sobre a estratégia de marcas próprias, gestão de suprimentos (compras) e o processo de seleção e avaliação de fornecedores.

\subsection{Estratégia de marcas próprias}

Com o intuito de esclarecer a distinção entre marca de fabricante e marca própria, entende-se que a marca de um fabricante é essencialmente de uso e posse dele, podendo ser vendida por diferentes varejistas ou atacadistas (PARENTE, 2000). Por sua vez, a marca própria, segundo Churchill e Peter (2000, p. 246), baseia-se na "marca de propriedade e uso de um atacadista ou varejista". A marca própria é "aquela que é possuída ou controlada, por meio de direitos de contrato, por uma empresa varejista, por um grupo filiado de varejistas ou por uma organização compradora" (STERN; EL-ANSARY, 1996, p. 326). Embora a fabricação fique a cargo da indústria, os direitos de propriedade e uso dos produtos são transferidos para os revendedores (atacadistas e ou varejistas) (BOWERSOX; COOPER, 1992) que se encarregam de gerenciar o produto com sua própria marca, vendendo-os exclusivamente em seus estabelecimentos (PARENTE, 2000; OLIVEIRA, 2005).

Segundo Shocker et al. (1994), Burt (2000), Oliveira e Machado (2003) a pressão do ambiente externo (competição e abertura do mercado global), o impacto da inovação tecnológica, mudanças no mercado consumidor e o aumento do poder dos distribuidores no canal (concentração econômica dos setores atacadista e varejista) motivaram a diferenciação das estratégias de comercialização dos distribuidores. Burt (2000) reporta que o desenvolvimento das marcas próprias (com destaque ao pioneirismo do Reino Unido) pode ser explicado por diversos fatores inter-relacionados que surgiram a partir da maior aproximação dos distribuidores às práticas de marketing.

A evolução do comportamento dos consumidores, que estão mais sensíveis ao preço e mais atentos à equi- 
valência na qualidade dos produtos, foi um importante fator impulsionador da estratégia de marcas próprias (KOTLER; KELLER, 2006). Mesmo porque, os fabricantes de marcas nacionais (tradicionais) enfraqueceram o valor de suas marcas ao reduzirem seus investimentos em marketing e ao disseminarem amplas extensões de marcas e linhas de produtos que provocaram distorção no conceito de suas marcas.

Desta forma, os problemas ocorridos no gerenciamento da marca de muitos fabricantes possibilitaram aos distribuidores (atacadistas e varejistas) a implementação efetiva da estratégia de marcas próprias (CHETOCHINE, 1999; WEBSTER Jr., 2000). A marca própria propiciou ao distribuidor maior controle sobre o composto mercadológico, incluindo qualidade do produto, preço e promoção (CHURCHILL; PETER, 2000). O controle mercadológico e o relacionamento mais intenso com os clientes, que relativamente os distribuidores já possuíam, tornaram-se ainda maior com a adoção da estratégia de marcas próprias.

As marcas próprias surgiram como evolução das marcas genéricas, também conhecidas como "marcas do dono da loja" que atualmente ainda podem ser encontradas em mercearias tradicionais e lojas de vizinhança (TAVARES, 1998; OLIVEIRA, 2005). Conforme Berkowitz et al. (2003), Kotler e Keller (2006), os produtos de marca genérica na verdade são versões sem marca dos produtos comuns (commodities), comercializados em embalagens simples. Geralmente, possuem qualidade padrão ou mesmo inferior e são comercializados a um preço entre $20 \%$ e $40 \%$ menor do que as marcas nacionalmente conhecidas (tradicionais); e entre $10 \%$ e $20 \%$ mais baixos que os das atuais marcas próprias (McGOLDRICK, 2005; KOTLER; KELLER, 2006). São os típicos produtos de primeiro preço, ou "o mais barato", que são desenvolvidos a um custo mínimo (BERKOWITZ et al., 2003) e que perderam sua popularidade por possuírem qualidade muito baixa (CHURCHILL; PETER, 2000).

Semelhante ao que ocorreu com as marcas genéricas, a marca própria inicialmente desenvolveu uma cultura de marca desfavorável a seu propósito. O mito de que os produtos de marca própria são mais baratos porque são de baixa qualidade foi um dos maiores entraves do desenvolvimento desta estratégia em muitos países (PIATO, 2006). No Brasil, por exemplo, os primeiros produtos com marcas próprias surgiram nas décadas de 1960 e 1970 e eram vistos como sendo de baixa qualidade (PARENTE, 2000; OLIVEIRA, 2005). Entendendo vários mercados como baseados principalmente em preço, os distribuidores desenvolveram produtos a um custo baixo, almejando o aumento da margem de lucro pela oferta de preços reduzidos aos clientes. Devido à baixa qualidade dos produtos, a marca própria desenvolveu nos clientes um sentimento de desconfiança (PIATO, 2006).
Entretanto, as marcas próprias, a pouco conquistaram seu espaço no mercado, tão logo as empresas passaram a agregar valor a suas marcas pelo desenvolvimento de atividades mercadológicas. A compra da marca própria aumentou na medida em que os clientes adquiriram conhecimento dos atributos da marca e perceberam como sendo reduzido o risco da compra de alguns produtos (BATRA; SINHA, 2000).

Atualmente, a importância das marcas próprias, principalmente no mercado de bens de consumo, está sendo comprovada por sua constante conquista de participação no mercado (STEINER, 2004). Segundo Conn (2005), os clientes gradativamente têm aceitado a idéia dos distribuidores desenvolverem marcas premium, exclusivas e de qualidade superior e que não são necessariamente mais baratas que as marcas tradicionais de fabricantes. Para Burt (2000), produtos de qualidade idêntica ou mesmo superior aos de marcas de fabricantes tornaram-se o principal elemento justificador do sucesso da estratégia de marcas próprias dos distribuidores.

Contudo, o sucesso da estratégia de marcas próprias, depende em grande parte da efetividade no gerenciamento de suprimentos, pois as marcas próprias são de propriedade e controle dos distribuidores, mas, em sua maioria, não são produzidas por eles. Isto significa que os distribuidores precisam de fabricantes que estejam dispostos a fornecer produtos para as marcas próprias.

Nesse sentido, a evolução da estratégia de marcas próprias, revela que muitos fabricantes encontram vantagens no fornecimento de produtos com a marca do distribuidor, tais como: reduzidas despesas de marketing (em alguns casos, em níveis próximos de zero), vendas e distribuição; o fabricante é "anônimo" (com exceções); permite redução de capacidade ociosa da fábrica; volume de produção/vendas assegurado por prazo definido; e, geralmente, é um negócio lucrativo com risco reduzido (SOUZA; NEMER, 1993). Assim, a aquisição dos produtos de marca própria passou a ser vista pelos distribuidores como atividade estratégica tão importante quanto o gerenciamento dos elementos de marketing que compõem a marca (PIATO, 2006).

\subsection{Gestão de suprimentos}

Entende-se primeiramente que supply chain (SC) é um conjunto de três ou mais entidades (organizações ou indivíduos) envolvido diretamente nos fluxos a montante e a jusante de produtos, serviços, finanças e/ou informação de uma fonte a um cliente (MENTZER et al., 2001). As atividades desempenhadas pelos fluxos em uma cadeia de suprimentos precisam ser gerenciadas entre as organizações que fazem parte da cadeia. Esta necessidade de "gestão" despertou muitos esforços de práticos e teóricos nas décadas de 1980 e 1990 na definição e estruturação 
do conceito originalmente entendido como supply chain management (SCM) (PIRES, 2004).

O conceito de SCM possui característica multidisciplinar, inerente ao processo de gestão que envolve diversas áreas do conhecimento (LAMBERT; COOPER, 2000). De acordo com a característica também multidisciplinar do objetivo proposto, foram adotadas neste artigo as perspectivas de marketing e de suprimentos (compras). Como estas são funções empresariais tradicionais, é conveniente, portanto, a adoção da definição de SCM proposta por Mentzer et al. (2001):

gestão da cadeia de suprimentos (SCM) é a coordenação sistêmica e estratégica das funções empresariais tradicionais e das táticas através das funções empresariais dentro de uma companhia particular e através dos negócios dentro da cadeia de suprimentos, com a finalidade de melhorar o desempenho no longo prazo das companhias individuais e da cadeia de suprimentos como um todo. (MENTZER et al., 2001).

O desdobramento desta definição permite a compreensão de que marketing e suprimentos são funções que integram este conceito. Em destaque, a função suprimentos (ou compras) é uma das "funções empresariais" (MENTZER et al., 2001) ou "silo funcional" (LAMBERT; COOPER, 2000) estrategicamente importante no gerenciamento do fluxo de produtos e materiais, sendo a área de compras, também atribuída à responsabilidade da administração de marketing, parte do escopo de atuação da SCM (PIRES, 2004).

Especificamente, a função suprimentos abrange a compra e a organização da movimentação de entrada de materiais, de peças e de produtos acabados dos fornecedores para fábricas ou montadoras, depósitos ou lojas de varejo, englobando operações de entrada tanto no recebimento de materiais quanto nas operações de separação ou montagem (BOWERSOX; CLOSS, 2001). Desta forma, define-se "gestão de compras ou suprimentos" como a função que lida com a interface da unidade produtiva e seus mercados fornecedores (SLACK et al., 2002).

Cabe ressaltar a importância que a gestão de suprimentos representa na cadeia de suprimentos. As decisões sobre compras impactam a eficiência com a qual as atividades logísticas no canal de suprimentos podem ser conduzidas (BALLOU, 2001). De acordo com Martins (1999), Alves (2001), Ballou (2001), Dantas et al. (2002) a função compras (ou suprimentos) envolve as atividades de: pesquisar produtos e serviços; localizar; selecionar e desenvolver fornecedores; classificar o desempenho do fornecedor; negociar preço e condições de pagamento; estabelecer contratos; emitir e acompanhar as ordens de compra (follow-up); controlar o recebimento do material para garantir as especificações solicitadas e avaliar o desempenho dos fornecedores quanto aos prazos de entrega e a qualidade do material fornecido. Martins (1999), Baily et al. (2000), Slack et al. (2002) reportam que os objetivos básicos dessas atividades resumem-se em: custo; prazo de entrega; quantidade; qualidade; e flexibilidade dos fornecedores.

De todas estas variáveis, a qualidade se destaca como um importante fator no monitoramento do desempenho dos fornecedores (BAILY et al., 2000) e no atendimento das necessidades do mercado. Por essa razão, as exigências de qualidade feitas ao fornecedor, vão muito além de atributos intrínsecos ao produto e abrange questões como: a qualidade de especificação (corresponde a uma indicação clara do propósito, função, aplicação e desempenho esperado do produto comprado que é comunicada ao fornecedor) e a qualidade de conformidade (que se refere à continuidade de entrega do produto conforme as especificações) (BAILY et al., 2000).

Assim, garantir a qualidade do produto por meio da seleção e monitoramento dos fornecedores destaca-se como importante requisito para que a empresa alcance seus objetivos, principalmente quando se refere à estratégia mercadológica de produtos que carregam a sua marca.

\subsubsection{Seleção e avaliação de fornecedores: aquisição de produtos para marca própria}

A estratégia de marca própria depende da relação do distribuidor com sua fonte de suprimento (ROSENBRÖIJER, 2001). Nesse sentido, para garantir a qualidade dos produtos de marca própria, a decisão sobre quem vai fabricar o produto determina, em parte, o sucesso da estratégia. Contudo, antes de determinar qual será a fonte de suprimento, o distribuidor precisa decidir sobre como o fabricante vai fornecer a marca própria.

Baily et al. (2000) apresentam duas situações em que o fabricante pode fornecer marca própria. Na primeira, o fabricante pode fornecer produtos de sua linha de produção padrão, ou seja, produtos idênticos aos comercializados por ele, mas com a marca do distribuidor. A outra situação é a "compra por especificação", na qual o revendedor especifica detalhadamente todos os atributos referentes a matérias-primas, processos, métodos de controle e qualidade. Batra e Sinha (2000) argumentam que especificações rígidas sobre a formulação dos produtos, os métodos de produção, selos de aprovação entre outras formas de garantia da qualidade industrial, ajudam a reduzir a incerteza do consumidor quanto à qualidade do produto de marca própria.

Todavia, na relação entre distribuidor e fabricante, existe interdependência de recursos que faz com que "o distribuidor controle sua marca própria sob um controle indireto do fabricante" (ROSENBRÖIJER, 2001, p. 11). Isso significa que mesmo quando o distribuidor deter- 
mina as especificações dos produtos, o fornecimento vai depender da análise da viabilidade de produção realizada pelo fabricante. Toillier (2003) alerta que mesmo que o fabricante tenha capacidade ociosa, a produção de marcas próprias pode envolver maiores complexidades de fabricação que podem aumentar os custos.

Desta forma, é necessário que o distribuidor selecione fornecedores dispostos e capazes de atender às suas especificações. Lambert et al. (1998) descrevem o seguinte procedimento para a seleção dos fornecedores: a) iden- tificar todos os fornecedores em potencial para o item a ser comprado e criar uma lista de fatores pelos quais cada fornecedor será avaliado; b) avaliar o desempenho de cada fornecedor individualmente para cada fator; c) determinar o peso de cada fator em sua situação específica; e d) comparar a soma dos pontos conquistados por cada fornecedor. A lista de fatores sugerida por Lambert et al. (1998) no procedimento de seleção representa o conjunto de critérios que os distribuidores julgam importantes para a escolha dos fornecedores. O Quadro 1 sintetiza os prin-

Quadro 1. Critérios utilizados para seleção de fornecedores; Fonte: elaborado a partir de Souza e Nemer (1993); Baily et al. (2000); Toillier (2003); Van Weele (2005); Blythe e Zimmerman (2005).

\section{Autores}

Baily et al. (2000)

Oliveira (2005)

Toillier (2003), Van Weele (2005)

Souza e Nemer (1993), Blythe e Zimmerman (2005)
- desempenho anterior: este método avalia os fornecedores por seu histórico de desempenho em transações anteriores; o comprador utiliza essa informação para selecionar os melhores fornecedores para avaliação;

- reputação: este método é amplamente utilizado por compradores experientes que identificam no fornecedor suas habilidades no mercado;

- proximidade do fornecedor: em muitos casos, a localização geográfica da fonte de suprimentos, passa a ser importante fator na medida em que impacta na determinação do custo logístico e na manutenção da qualidade de determinados produtos;

- apoio promocional: o distribuidor pode requerer algum tipo de apoio promocional do fornecedor com relação às marcas próprias; por isso, é importante que o fabricante possua suporte de marketing para desenvolver ações promocionais em conjunto com o detentor da marca.

- certificação de terceiros: é a visita ao fornecedor de uma organização independente contratada pelo comprador e/ou fornecedor que avaliará a qualidade do fornecedor e disponibilizará os resultados na forma de certificação da qualidade;

- visita e avaliação: envolve uma visita do comprador ao fornecedor para avaliar sua capacitação em produzir/fornecer com qualidade; a visita avalia os sistemas de produção e as instalações, inspeciona os instrumentos de medição da produção, e promove a checagem e avaliação das rotinas de mensuração e de outros dispositivos de teste; esse método despende mais tempo e pode custar mais caro que os demais; e

- avaliação de amostras de produtos: os produtos oferecidos pelo fornecedor serão avaliados por seu desempenho final.

- verificação da idoneidade e credibilidade do fornecedor;

- levantamento da estabilidade financeira e situação fiscal;

- análise da capacidade produtiva, ociosa e de instalação;

- comparação do grau de competitividade da fábrica e do produto;

- levantamento do histórico do fornecedor nos últimos anos;

- análise do tamanho da empresa;

- auditoria da fábrica;

- verificação da capacidade de manutenção da qualidade final do produto;

- análise do sistema de logística nacional; e

- verificação do sistema de atendimento aos consumidores nacionalmente.

- responsabilidade e segurança do produto: os revendedores podem requerer que os fabricantes se responsabilizem por problemas na qualidade do produto, principalmente no que se refere às questões éticas e ambientais, uma vez que problemas desta ordem podem afetar diretamente o nome e a imagem do distribuidor.

- atendimento ao cliente: atender às reclamações dos clientes assumindo as eventuais despesas de troca ou manutenção de produtos; contudo, é comum essa responsabilidade ser dividida entre o detentor da marca e o fabricante.

- acordos de longo prazo: o investimento em relacionamentos de longo prazo reduz o risco do negócio e a complexidade do relacionamento com o fornecedor; desta forma, o estabelecimento de acordos recíprocos de longo prazo é uma forma de garantir o padrão de qualidade dos produtos e o abastecimento regular. 
cipais critérios sugeridos pela literatura para a seleção de fornecedores.

Estabelecidos os critérios, o fornecedor será selecionado segundo um conjunto de habilidades, representado por suas capacidades tecnológicas (de projeto/produto, de processo e fabricação e de gestão), em atender às especificações para conformidade do produto, de entrega (tempo e forma de entrega) e de custos (redução de preço dos produtos adquiridos) (MARTINS, 1999). Para Oliveira (2005), o ideal é mesclar os critérios de seleção optando prioritariamente por aqueles que atendam às necessidades do comprador.

Toillier (2003) e Van Weele (2005) concluem que é imperativo o estabelecimento de acordos contratuais que definam os termos e as condições relacionados ao preço, forma de estocagem, tamanho do pedido, forma de pagamento, prazo de entrega, controle de qualidade e segurança do produto, garantias envolvidas e duração do contrato, para estabelecer vínculo comercial.

Por fim, o desempenho do fornecedor selecionado deve ser constantemente monitorado, utilizando-se os mesmos critérios de seleção, pois são estes que atendem às necessidades especificadas pelos compradores. Assim, após a seleção do fornecedor, freqüientes auditorias de produção com inspeção no controle de qualidade (produto, embalagem, experimentação em teste cego) (OLIVEIRA, 2005) ajudam a monitorar o desempenho do fornecedor que deve seguir todas as especificações estabelecidas no contrato de fornecimento.

\section{Metodologia}

Este estudo é parte de uma pesquisa maior, ainda em andamento, que tem como objetivo analisar comparativamente as estratégias de marca de atacadistas e varejistas que atuam com marcas próprias. $\mathrm{O}$ estudo também possui uma parte internacional, na qual os autores comparam a estratégia de marcas próprias de varejistas do Brasil e do Reino Unido. Neste artigo, explorou-se apenas o seguinte objetivo específico: compreender os impactos da gestão suprimentos na estratégia de marcas próprias do atacado, analisando os procedimentos e critérios utilizados pelos atacadistas para a seleção e avaliação de fornecedores de marcas próprias.

O método de investigação empírica deste estudo está classificado como exploratório, pois nenhuma pesquisa anterior focalizou a estratégia de marcas próprias no setor atacadista e suas relações com a função suprimentos. Desta forma, optou-se pela utilização do método de estudo de caso, pois, segundo Triviños (1992), dentro do enfoque qualitativo, o método de estudo de caso se apresenta como uma das formas mais relevantes de pesquisa. Segundo Gil (1996) e Aaker et al. (2004), a maior utilidade do estudo de caso é verificada nas pesquisas exploratórias, nas quais existe a necessidade de se realizar investigações iniciais acerca de novas problemáticas.

Os resultados empíricos apresentados neste artigo estão baseados na análise qualitativa de dados de entrevistas realizadas no ano de 2006 com gerentes de marcas próprias de três empresas atacadistas brasileiras e com diretores de duas indústrias fornecedoras. Optou-se pelo estudo de casos múltiplos (três empresas especificamente no atacado e duas indústrias fornecedoras) porque possuem a vantagem de fornecer resultados mais convincentes, devido à maior abrangência do estudo. Segundo Yin (2001), a utilização de casos múltiplos deve seguir a lógica da replicação, ou seja, os casos devem produzir resultados similares ou contraditórios entre si. Neste estudo, a investigação sobre o processo de seleção e avaliação dos fornecedores de marcas próprias denotou o reconhecimento de um padrão (pattern recognition) entre os procedimentos adotados pelas empresas atacadistas.

O critério de escolha dos atacadistas foi baseado na observação do Ranking ABAD 2006 (ranking da Associação Brasileira de Atacadistas e Distribuidores, realizado pela A.C.Nielsen) que categorizou e avaliou o desempenho das empresas atacadistas brasileiras. Optou-se por selecionar as três maiores empresas do ranking que possuíam marcas próprias, independentemente do tipo (formato) de atacado. As duas indústrias fornecedoras escolhidas foram indicadas pelos próprios atacadistas do estudo. Como forma de controlar a fidedignidade dos dados obtidos sobre o processo de seleção e avaliação de fornecedores, as entrevistas realizadas nas duas indústrias fornecedoras possuíram o objetivo de confirmar as características do processo de seleção e avaliação realizado pelos atacadistas. Desta forma, o procedimento de escolha dos atacadistas e fornecedores estudados, caracterizou-se como intencional (TRIVIÑOS, 1992), comum a estudo qualitativo-exploratório.

Os três atacadistas identificados neste artigo como atacadistas A, B e C, cujos nomes não serão divulgados a pedido deles, concentram a maior quantidade de itens e categorias de marcas próprias do setor atacadista brasileiro. A representatividade dessas três empresas no mercado nacional de marcas próprias é pequena (quando comparado ao setor varejista), porém, muito significativa em relação ao setor atacadista, conforme mostra a Figura 1.

As entrevistas realizadas com o gerente de marcas próprias de cada atacadista foram orientadas por um roteiro semi-estruturado elaborado pelos autores a partir do referencial teórico pesquisado. Entre as possíveis técnicas de entrevista optou-se pela realização de uma entrevista pessoal em profundidade, na qual pesquisador e entrevistado ficaram frente a frente explorando em detalhes o assunto-objeto da entrevista (AAKER et al., 2004). As entrevistas realizadas foram do tipo não diretiva, também conhecida como entrevista semi-estruturada. 


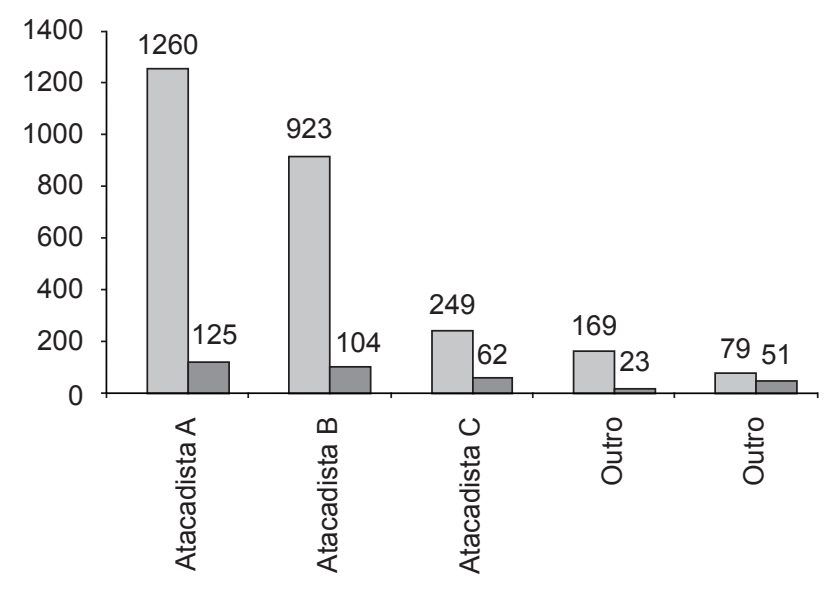

Número de itens

Número de categorias

Figura 1. Número de itens e categorias de marcas próprias no atacado brasileiro em 2004-2006. Elaborada a partir de Piato (2006, p. 120) e Oliveira (2005, p. 208).

Segundo Triviños (1992), a entrevista semi-estruturada parte de certos questionamentos básicos, apoiados na teoria, contudo não é estruturada estaticamente, o que permite flexibilidade na sua condução. Assim, o entrevistado possuiu a liberdade de seguir espontaneamente a linha de seu pensamento.

Em entrevistas semi-estruturadas, os roteiros são igualmente semi-estruturados. Assim, os roteiros foram elaborados conforme Triviños (1992) e Pádua (1997) sugerem: primeiro, foi elaborado um grupo de questões direcionadas à identificação dos entrevistados; em seguida, foi construído o rol de tópicos com questões objetivas descritivas e não dicotômicas ( $\mathrm{sim} /$ não), formuladas a partir da revisão bibliográfica. Ressalta-se que os roteiros de entrevista foram pré-testados em estudo piloto realizado com um atacadista, que compõe uma das unidades-caso desta pesquisa (corresponde ao atacadista A) e em uma indústria fornecedora de marca própria, que também faz parte desta pesquisa. Todas as cinco entrevistas realizadas, sendo três delas com gerentes de marcas próprias (um gerente de cada atacadista) e outras duas com diretores de produção (um diretor de cada indústria fornecedora) foram gravadas e depois transcritas.

$\mathrm{Na}$ análise e interpretação dos dados, procurou-se ir além da apresentação organizada deles, estabelecendo cuidadosamente relações entre teoria e prática. Assim, os dados obtidos por meio das entrevistas foram analisados qualitativamente pelo emprego de técnicas de análise comparativa dos procedimentos adotados por cada atacadista. As informações geradas também foram comparadas com as considerações realizadas pelos diretores das indústrias fornecedoras que, por fim, foram comparadas à revisão da literatura. Desta forma, foi possível sintetizar os procedimentos utilizados para sele- cionar e avaliar os fornecedores de produtos de marcas próprias. Ao final da pesquisa, esperava-se estruturar um quadro com a sequiência dos procedimentos de análise, que integram os critérios de seleção e avaliação impostos pelos atacadistas aos fabricantes que compõem ou que pretendem compor o grupo de fornecedores dos produtos de marcas próprias.

\section{Apresentação e discussão dos casos}

Para a compreensão do impacto da função suprimentos na estratégia de marcas próprias, esta seção sintetiza a visão das três empresas atacadistas (A, B e C) sobre processo de seleção e avaliação de fornecedores de marcas próprias. Ressalte-se que, para fins comparativos, o processo de seleção e avaliação de fornecedores de marcas próprias apontados pelos três atacadistas e confirmados pelas duas indústrias fornecedoras, também foram analisadas com base na revisão teórica apresentada na seção 2 .

\subsection{Características dos atacadistas estudados}

O setor atacadista (comércio atacadista ou distribuição atacadista) está intimamente associado ao gerenciamento de bens tangíveis; contudo, o atacado agrega valor por meio do fornecimento de serviços no fluxo do canal (COUGHLAN et al., 2002) e, mais recentemente, pelo desenvolvimento de marcas próprias. Define-se o atacado como:

as atividades das pessoas ou dos estabelecimentos que vendem a varejistas e/ou outros compradores organizacionais para uso industrial, institucional ou comercial, mas não vendem para consumidores finais. (DUNNE; LUSCH, 2001, p. 348).

A principal característica dos atacadistas é suas transações comerciais serem efetuadas no âmbito empresarial, pois eles compram e vendem produtos dos quais assumem a posse (COUGHLAN et al., 2002), os riscos (BOWERSOX; CLOSS, 2001) e possuem autoridade na definição de preços. Todavia, existem vários tipos e formatos de atacadistas que podem desempenhar total ou parcialmente estas funções. Neste estudo, foram analisados três atacadistas mercantis (de mercadorias ou tradicionais), que estão classificados em dois tipos (ou formatos) (CZINKOTA et al., 2001):

Atacadista A: atacadista mercantil do tipo serviços limitados; desempenham apenas algumas funções inerentes ao atacado; eles compram, estocam e fracionam a mercadoria, mas não prestam serviço de entrega, nem concedem crédito ao comprador; por isso, também são conhecidos como atacadistas de auto-serviço, ou do tipo cash-and-carry.

Os atacadistas de auto-serviço não possuem equipe de vendas, nem estrutura de entrega. A mercadoria é exposta em prateleiras ou pallets e oferecida nas embalagens de 
embarque originais (da indústria) ou em embalagens menores fracionadas pela indústria ou pelo próprio atacadista. Nesse formato, os clientes precisam buscar as mercadorias na loja/armazém do atacadista e pagar por elas à vista. Geralmente, esses atacadistas são visitados por pequenos varejistas e pequenos clientes industriais. Este formato, que possui muitas características do varejo, está em expansão nos grandes centros do Brasil.

Atacadistas B e C: atacadistas mercantis do tipo serviços completos; atuam como atacadistas distribuidores de mercadorias gerais; esses gerenciam equipe de vendas e possuem uma estrutura logística de distribuição.

Os atacadistas de serviços completos desempenham praticamente todas as funções inerentes ao atacado. Eles compram e estocam as mercadorias, fracionam e entregam no armazém/loja do cliente, concedem crédito e serviços especiais, além de manter equipe de vendas que periodicamente visita os clientes.

\subsection{Gestão de suprimentos no atacado: a compra da marca própria}

Como indicado na revisão da literatura, a compra dos produtos de marcas próprias é atividade essencial para a eficácia da estratégia. Os atacadistas estudados atribuíram ao processo de compra dos produtos de marcas próprias o status de "função-chave" da estratégia, uma vez que eles afirmam possuir maior domínio e habilidade no desempenho dessa função (competência central). Apenas para retratar as atividades que envolvem a função compras, serão apresentadas brevemente algumas considerações sobre esse processo.

A gestão de compras (ou gestão de suprimentos) dos atacadistas estudados é comparável às atividades descritas por Dantas et al. (2002) e Alves (2001). Ou seja, envolve todo o processo de planejamento das necessidades de localização e seleção de fornecedores, aquisição de mercadorias por meio de negociações de preço e condições de pagamento, bem como o acompanhamento do processo junto ao fornecedor escolhido e recebimento, inspeção, armazenagem e manuseio das mercadorias para controlar e garantir o funcionamento do processo dentro das especificações. Os objetivos da gestão de compras dos atacadistas também são os mesmos descritos por Martins (1999), Baily et al. (2000) e Slack et al. (2002): custo; prazo de entrega; volume; qualidade; e flexibilidade dos fornecedores.

Os atacadistas estudados consideram corriqueiras e habituais todas as atividades supracitadas, pois são atividades inerentes às funções de qualquer atacadista tradicional. Independente de a compra ser de produtos de marcas de fabricantes ou de marcas próprias, essas atividades são desempenhadas da mesma forma e com os mesmos critérios. Assim, os acordos de prazo e tipo de entrega (loja-a-loja, ou em centro de distribuição) volume e preço, estão firmados em contratos comerciais padronizados, estabelecidos tanto para os produtos de marca de fabricante quanto para os produtos de marcas próprias.

Com ressalva, no caso das marcas próprias os atacadistas assinam com o fornecedor um "acordo de fornecimento", no qual estão determinadas algumas cláusulas específicas para o desenvolvimento das marcas próprias, tais como:

a) a marca é de propriedade do atacadista;

b) o fornecedor não pode comercializar a marca própria com nenhum outro agente;

c) será realizada periodicamente auditoria de fábrica para averiguação dos requisitos de qualidade do produto; e

d) não deverá haver excedente em estoque de produtos de marca própria, além do nível determinado pelo atacadista.

As cláusulas desse acordo são formalizadas em um contrato, ou anexadas ao contrato que por ventura já exista (caso o fornecedor também forneça suas marcas de fabricante ao atacadista), em que as típicas questões comerciais são tratadas. Normalmente, os contratos que os atacadistas mantêm com seus fornecedores de marcas próprias possuem duração média de doze meses e podem ser renovados conforme o interesse de ambas as partes. Assim, se ninguém se manifestar para um rompimento, o contrato de fornecimento permanece por tempo indeterminado.

De acordo com os gerentes entrevistados, os fornecedores de marcas próprias precisam manter um acordo de fornecimento de longo prazo, pois não será interessante para eles fazerem parte de um acordo de curta duração, uma vez que os fornecedores precisam arcar com custos de desenvolvimento de produtos, embalagens e de ajustes na linha de produção. Por conseqüência, também é importante para os atacadistas um acordo de longo prazo, uma vez que os fornecedores selecionados foram escolhidos por atender aos muitos critérios de fornecimento estabelecidos pelos atacadistas que vêem, na continuidade da relação, uma maneira de manter o nível de qualidade dos produtos de marcas próprias.

\subsection{Processo de seleção e avaliação dos fornecedores de marcas próprias do atacado}

A preocupação com o nível de qualidade dos produtos de marcas próprias faz com que o processo de seleção e avaliação da fonte de suprimentos (fornecedores) seja a atividade mais importante da função compras na estratégia de marcas próprias dos atacadistas. Assim, selecionar fornecedores qualificados para produzir os produtos de marcas próprias, é um aspecto crítico da estratégia, uma vez que coloca em jogo a imagem e a credibilidade dos atacadistas. Para os gerentes entrevis- 
tados, "comprar bem, significa exatamente escolher bem os fornecedores".

Dessa forma, estão descritos a seguir, os principais critérios de seleção dos fornecedores de marcas próprias dos atacadistas estudados. Ressalta-se que todos os critérios analisados pelos atacadistas no processo de seleção, também foram confirmados pelas duas indústrias fornecedoras que também fizeram parte desta pesquisa, justamente com o propósito de se estabelecer essa confirmação.

De acordo com os gerentes entrevistados, podem existir duas situações de compra de marcas próprias. Na primeira situação, a partir do momento em que os atacadistas identificam a necessidade de selecionar um fornecedor para determinado produto de marca própria, eles procuram analisar, primeiramente, dois aspectos: desempenho anterior e reputação (experiência). Ressalta-se que esses aspectos também foram mencionados por Baily et al. (2000) no Quadro 1.

a) desempenho anterior: são privilegiados os fornecedores que já possuam um relacionamento anterior com os atacadistas; isso facilita a negociação dos critérios estabelecidos nos acordos comerciais como custo, preço, prazo e tipo de entrega, pois esses fornecedores já conhecem a dinâmica comercial dos atacadistas, o que torna mais fácil o diálogo no estabelecimento do acordo de suprimento de marcas próprias;

b) reputação (ou experiência): é dada preferência a fornecedores tradicionais que possuam experiência anterior no fornecimento de marcas próprias, principalmente se forem fabricantes de marcas líderes de mercado (marcas de referência), pois torna o processo de desenvolvimento da marca própria mais rápido e confiável.

Entretanto, caso não sejam encontrados fornecedores que já possuam relação comercial antecedente com os atacadistas, é necessário recrutar outros fornecedores no mercado. Nessa segunda situação, os gerentes dos atacadistas estudados se consideram muito criteriosos e adotam os procedimentos e os critérios descritos seqüencialmente no Quadro 2. Observe que na coluna "descrição do processo" do Quadro 2, são citados alguns autores que mencionam tais critérios. É importante ressaltar que o Quadro 2 é a principal contribuição deste artigo, pois relaciona os procedimentos e critérios relatados igualmente pelos três atacadistas estudados e confirmados pelos dois fornecedores que também participaram deste estudo.

Segundo os gerentes entrevistados, os procedimentos e critérios descritos no Quadro 2 possuem caráter geral, porém, são os mais importantes no processo de seleção dos fornecedores. Contudo, existe uma série de outros fatores que também podem ser levados em consideração durante o processo de seleção. Um dos fatores mencionados por Baily et al. (2000) e que foi confirmado por dois dos atacadistas estudados (A e B), é o oferecimento de apoio promocional por parte dos fornecedores. Segundo os gerentes desses atacadistas, embora não seja diretamente exigido dos fornecedores apoio promocional, alguns deles se comprometem em oferecer algum tipo de material de comunicação como, por exemplo, o desenvolvimento de jornais de ofertas de sua marca de fabricante em conjunto com as marcas próprias.

Outro fator importante que também pode ser analisado durante o processo de seleção do fornecedor, está relacionado à preocupação com a manutenção da qualidade do produto em situações adversas de custos. Como mencionado anteriormente, para alguns produtos, apenas a embalagem é modificada e o produto mantém-se idêntico ao distribuído com a marca do fabricante/fornecedor. Entretanto, existem casos nos quais é necessário que os atacadistas, em conjunto com o fornecedor, alterem a composição do produto desenvolvendo-o de acordo com as exigências de custo e qualidade determinadas pelos atacadistas. Assim, no acordo de fornecimento da marca própria, a manutenção da qualidade do produto é tão importante para os atacadistas, que existe freqüente preocupação quanto a possível rompimento ou quebra de confiança por parte do fornecedor.

Segundo os atacadistas, selecionar outro fornecedor capaz de oferecer um produto com o mesmo nível de qualidade sem que os clientes/consumidores percebam qualquer diferença, passa a ser um grande desafio. Mesmo porque, quando o fornecimento é interrompido ou abalado por queda na qualidade dos produtos, podem ser irreversíveis os prejuízos ocasionados pela falta de reposição dos produtos na gôndola dos clientes. Os gerentes destacam que o tempo gasto para realização do processo de seleção do novo fornecedor, bem como para o desenvolvimento e fabricação dos produtos e das embalagens, é muito grande.

A questão da proximidade e localização geográfica dos fornecedores (BAILY et al., 2000) para um dos atacadistas estudados, é outro fator importante no processo de seleção. Nesse caso, o atacadista A, por exemplo, não possui um centro de distribuição (CD) e nem logística centralizada. Por essa razão, ele depende muito dos seus fornecedores, os responsáveis pela entrega dos produtos nos armazéns/ lojas do atacadista. Dessa forma, pequenos fornecedores muitas vezes ficam impossibilitados (por restrições de alcance geográfico) em atender aos requisitos de entrega do atacadista A. Por consequiência, o atacadista A procura desenvolver acordos de fornecimento com fornecedores maiores (médio-grande porte) e mais tradicionais, aproveitando sua logística de distribuição.

Devido às dimensões geográficas do Brasil, o principal desafio sobre a questão da proximidade dos fornecedores para o atacadista A, baseia-se em encontrar apenas um fabricante que forneça toda a produção necessária para atender 
Quadro 2. Processo de seleção e avaliação de fornecedores de marcas próprias dos atacadistas estudados; Fonte: elaborado pelos autores a partir dos casos analisados.

\begin{tabular}{|c|c|c|}
\hline Procedimento & Critérios de seleção & Descrição do processo \\
\hline $\begin{array}{l}\text { Pré-seleção de } \\
\text { fornecedores }\end{array}$ & $\begin{array}{l}\text { - recomendações da rede de con- } \\
\text { tatos; } \\
\text { - informações de mercado; } \\
\text { - certificação de terceiros. }\end{array}$ & $\begin{array}{l}\text { Os atacadistas procuram pré-selecionar alguns fornecedores para avaliação; } \\
\text { esses fornecedores podem ser indicados por indústrias, clientes, revistas e por } \\
\text { outros contatos dos atacadistas; eles também podem ser recrutados por meio } \\
\text { de pesquisa de mercado realizada por empresas especializadas que pré-sele- } \\
\text { cionam alguns fornecedores para avaliação (certificação de terceiros, BAILY } \\
\text { et al., 2000); essas empresas fazem uma auditoria (de fábrica, processos, } \\
\text { qualidade dos produtos, etc.) dos fornecedores estabelecendo uma pontuação a } \\
\text { cada fornecedor avaliado (procedimento descrito por LAMBERT et al., 1998) } \\
\text { e informam aos atacadistas os resultados de sua certificação. }\end{array}$ \\
\hline \multirow[t]{3}{*}{$\begin{array}{l}\text { Análise do } \\
\text { histórico dos } \\
\text { fornecedores }\end{array}$} & $\begin{array}{l}\text { - reputação e experiência; } \\
\text { - possuir marca de fabricante reco- } \\
\text { nhecida no mercado. }\end{array}$ & $\begin{array}{l}\text { Os atacadistas também analisam se os fornecedores já produzem marcas } \\
\text { próprias para outros revendedores ("reputação", BAILY et al., 2000); essa } \\
\text { experiência anterior é um critério que facilita o acordo entre as partes; nesse } \\
\text { sentido, outro aspecto verificado, mas sem muita rigidez, é se os fornecedores } \\
\text { possuem uma marca de fabricante com expressividade no mercado (marcas } \\
\text { líderes); isso traz certa tranqüilidade aos atacadistas quanto à qualidade dos } \\
\text { produtos oferecidos e torna a escolha mais fácil. }\end{array}$ \\
\hline & $\begin{array}{l}\text { - idoneidade e credibilidade do } \\
\text { fornecedor; } \\
\text { - responsabilidade sócio-ambiental. }\end{array}$ & $\begin{array}{l}\text { Os atacadistas também verificam alguns aspectos sobre a idoneidade ética } \\
\text { e moral dos fornecedores, pois isso pode afetar a imagem da marca própria; } \\
\text { como exemplo, o uso de trabalho infantil em uma carvoaria que fornece car- } \\
\text { vão com a marca dos atacadistas (OLIVEIRA, 2005). }\end{array}$ \\
\hline & $\begin{array}{l}\text { - averiguação da situação e estabili- } \\
\text { dade financeira do fornecedor. }\end{array}$ & $\begin{array}{l}\text { A situação financeira dos fornecedores é importante indicativo para os ata- } \\
\text { cadistas avaliarem as possibilidades de quebra de confiança nos acordos de } \\
\text { fornecimento (exemplo: alterar a qualidade dos produtos para economizar nos } \\
\text { custos de produção sem comunicar aos atacadistas). }\end{array}$ \\
\hline $\begin{array}{l}\text { Contato } \\
\text { preliminar }\end{array}$ & $\begin{array}{l}\text { - colocação das condições contratu- } \\
\text { ais de longo prazo. }\end{array}$ & $\begin{array}{l}\text { Os fornecedores pré-selecionados são convidados para um primeiro contato } \\
\text { com os atacadistas, no qual são discutidas de maneira transparente todas as } \\
\text { exigências e a forma de trabalho de ambos. }\end{array}$ \\
\hline $\begin{array}{l}\text { Visita à fábrica } \\
\text { dos fornecedores }\end{array}$ & $\begin{array}{l}\text { - análise da capacidade produtiva, } \\
\text { ociosa e de instalação; } \\
\text { - análise do sistema de logística } \\
\text { nacional; } \\
\text { - análise da capacidade de manu- } \\
\text { tenção da qualidade do produto; } \\
\text { - análise do ambiente empresarial. }\end{array}$ & $\begin{array}{l}\text { Além da auditoria realizada por empresas terceirizadas, os gerentes e a equipe } \\
\text { técnica dos atacadistas também fazem uma visita à fabrica dos fornecedores } \\
\text { (BAILY et al., 2000) e avaliam aspectos importantes da produção (equipa- } \\
\text { mentos, processos, manual de boas práticas), nível tecnológico e logístico } \\
\text { (exemplo: rastreamento do produto), aspectos organizacionais (funcionários, } \\
\text { estrutura física e departamental) e principalmente, os sistemas de controle de } \\
\text { qualidade (OLIVEIRA, 2005). }\end{array}$ \\
\hline $\begin{array}{l}\text { Solicitação de } \\
\text { amostras do } \\
\text { produto }\end{array}$ & $\begin{array}{l}\text { - requerimento de laudos técnicos } \\
\text { dos produtos e de documentação } \\
\text { fiscal. }\end{array}$ & $\begin{array}{l}\text { Os atacadistas solicitam aos fornecedores o envio de algumas amostras do pro- } \\
\text { duto para avaliação, bem como seus laudos técnicos e a documentação exigida } \\
\text { por órgãos reguladores; essa análise das amostras do produto, geralmente, } \\
\text { segue as especificações de uma ficha técnica pautada nos padrões de órgãos } \\
\text { reguladores e, às vezes, nas especificações técnicas exigidas pelos próprios } \\
\text { atacadistas. }\end{array}$ \\
\hline $\begin{array}{l}\text { Avaliação das } \\
\text { amostras }\end{array}$ & $\begin{array}{l}\text { - análise comparativa das amostras } \\
\text { dos produtos; } \\
\text { - realização de teste cego. }\end{array}$ & $\begin{array}{l}\text { Os atacadistas realizam uma criteriosa avaliação das amostras dos produtos; } \\
\text { essa avaliação é na maior parte dos casos, uma análise comparativa, ou seja, as } \\
\text { amostras são submetidas à avaliação ou experimentação (no caso de alimen- } \\
\text { tos) pelo denominado "teste cego" que procura avaliar, anonimamente, o } \\
\text { desempenho e a qualidade das amostras em relação aos produtos de referência } \\
\text { (geralmente a marca líder) (BAILY et al., 2000; OLIVEIRA, 2005). }\end{array}$ \\
\hline $\begin{array}{l}\text { Apresentação } \\
\text { das propostas }\end{array}$ & $\begin{array}{l}\text { - comparação do grau de competiti- } \\
\text { vidade do fornecedor e do produto. }\end{array}$ & $\begin{array}{l}\text { Os atacadistas solicitam aos fornecedores o envio de suas propostas de custo } \\
\text { total unitário (valor por unidade produzida), para que sejam avaliadas as me- } \\
\text { lhores relações custo/benefício dos produtos. }\end{array}$ \\
\hline $\begin{array}{l}\text { Escolha do } \\
\text { fornecedor }\end{array}$ & $\begin{array}{l}\text { - condição de equilíbrio entre todos } \\
\text { os critérios avaliados. }\end{array}$ & $\begin{array}{l}\text { A escolha final do fornecedor, depende do equilíbrio buscado pelos atacadistas } \\
\text { entre os principais aspectos analisados, tais como custo de produção, quali- } \\
\text { dade dos produtos, confiança e principalmente atitude; para os atacadistas é } \\
\text { importante que o fornecedor esteja realmente interessado e comprometido } \\
\text { com aquilo que está propondo. }\end{array}$ \\
\hline
\end{tabular}


os clientes regionalmente dispersos. Para o atacadista A, quanto maior o alcance logístico do fornecedor escolhido, melhor será a manutenção da qualidade do produto. Entretanto, existem casos em que, mesmo um fornecedor bem localizado não possui condições de atender determinadas regiões distantes, pois o custo total do produto em relação ao preço de venda se torna excessivo e o produto deixa de ser competitivo. Desta forma, é necessário selecionar outro fabricante para fornecer o mesmo produto, no mesmo padrão de qualidade. Essa é uma preocupação que mais uma vez realça a importância do processo de seleção do fornecedor de marcas próprias.

$O$ fator não confirmado pelos atacadistas estudados e sugerido pela literatura (TOILLIER, 2003; Van WEELE, 2005; OLIVEIRA, 2005) refere-se ao atendimento dos clientes imediatos após a compra. Os atacadistas não exigem que os fornecedores se encarreguem desse serviço, pois eles consideram que esse contato com os clientes é muito importante, mesmo em casos de reclamações. Assim, os fornecedores apenas serão requisitados se houver algum tipo de problema na qualidade e ou segurança dos produtos.

Com relação à avaliação do desempenho dos fornecedores escolhidos, os atacadistas estudados afirmaram que são utilizados alguns dos procedimentos adotados no próprio processo de seleção dos fornecedores. Assim, um fornecedor pode ser desabilitado no momento em que a avaliação de seu desempenho não satisfizer os critérios de custo, prazo, forma de entrega e principalmente de qualidade que foram estipulados no acordo de fornecimento das marcas próprias. Segundo os gerentes entrevistados, qualidade é o fator mais monitorado pelos atacadistas, uma vez que os outros fatores habitualmente são rotineiros e controlados pelos departamentos comerciais.

Dessa forma, os atacadistas avaliam a qualidade dos produtos de marcas próprias por meio de visitas periódicas às fábricas (auditoria de fábrica), que são realizadas no mínimo uma vez ao ano, ou periodicamente em tempo reduzido, o que depende da sensibilidade e das características do produto em questão. Também é realizada, avaliação, experimentação ou degustação (no caso de alimentos) por "teste cego", para avaliar o desempenho e a qualidade dos produtos durante o período de fornecimento. Segundo os atacadistas estudados, raramente os fornecedores são reprovados durante os procedimentos de avaliação. Para eles, um criterioso processo de seleção do fornecedor é fundamental para minimizar as probabilidades de ocorrerem futuros problemas de fornecimento.

\section{Considerações finais e sugestões para pesquisas futuras}

Este estudo contribuiu para a compreensão da importância da gestão de suprimentos na estratégia de marketing de empresas comerciais, não manufatureiras. Com base no objetivo proposto, pode-se concluir que o desempenho da função suprimentos, com destaque para o processo de seleção e avaliação dos fornecedores, é essencial para a eficácia da estratégia de marcas próprias, não só porque este seja um elemento crítico, mas porque a escolha da fonte de suprimento influencia o gerenciamento de outros elementos que compõem esta estratégia.

O detalhamento dos procedimentos e critérios (ou fases) utilizados no processo de seleção e avaliação de fornecedores demonstrou haver preocupação dos atacadistas com esse aspecto, pois, assim como menciona Baily et al. (2000), os atacadistas reconhecem que a decisão tomada sobre "o que comprar", recai imediatamente sobre "o que vender". Por essa razão, os atacadistas e os fornecedores entrevistados confirmaram uma tendência já apontada pelo trabalho desenvolvido por Alcântara (1997) que indicou um movimento nos canais de distribuição direcionado para a formação de relacionamentos mais cooperativos entre o atacado e a indústria produtora. No caso do acordo de fornecimento de marcas próprias, a atuação conjunta entre atacadistas e fornecedores no desenvolvimento dos produtos, estimulada pelo compartilhamento de objetivos e por relações amistosas do tipo ganha-ganha, é aspecto fundamental para o sucesso da estratégia de marcas próprias.

É importante destacar que a confluência de áreas do conhecimento aparentemente distintas (marketing e suprimentos), permite que os elementos condicionantes para a eficácia da estratégia de marcas próprias, sejam mais bem desenvolvidos. Neste caso, ressalta-se a importância da empresa possuir uma cultura de marketing orientada para o mercado, na qual o departamento de compras, entre outras funções, precisa estar integrado e comprometido com a estratégia. Deste modo, a função suprimentos procura buscar proativamente os melhores fornecedores, construindo relações de longo prazo mais confiáveis e de melhor qualidade, além de não comprometer a qualidade da compra na busca de economias em preço (KOTLER; KELLER, 2006).

Assim, foi constatado que a função suprimentos é crucial para a estratégia de marcas próprias do atacado, pois os atacadistas estudados afirmaram que todas as atividades que compõem o processo de seleção e avaliação dos fornecedores, são fatores determinantes para garantir a eficácia dessa estratégia.

Como forma de reconhecer o caráter restrito deste estudo multicaso, é preciso destacar alguns pontos que o limitam:

a) primeiramente, o método de estudo escolhido apresenta algumas limitações inerentes à natureza do próprio método; assim, por se tratar de estudo multicaso, as considerações feitas no estudo empírico, apresentam análise específica das empresas 
estudadas sobre a estratégia de marcas próprias e, portanto, se limita às considerações dessas empresas; quaisquer tipos de generalizações devem ser contidas ou realizadas com cautela evitando-se possíveis distorções; e

b) outra limitação também se relaciona ao método de abordagem; a realização de entrevistas pessoais possui tanto o viés do entrevistado quanto o dos pesquisadores; neste sentido, destaca-se que existe a possibilidade de os gerentes entrevistados terem falseado algumas respostas para, de alguma forma não comprometer a empresa; da mesma forma, embora as entrevistas tenham sido gravadas, os pesquisadores podem ter interpretado mal algumas respostas, causando distorções na análise.

Para a realização de pesquisas futuras, sugere-se a realização de outras análises sobre o impacto das ativi- dades relacionadas à função suprimentos nas estratégias de marcas próprias dos atacadistas. Em especial, sugere-se a realização de estudos que analisem especificamente o padrão de relacionamento entre fornecedores de marcas próprias e atacadistas, pois o comprometimento entre os agentes é fundamental para que os objetivos dessa estratégia sejam alcançados. Sugere-se também, a realização de estudos que possam ampliar o escopo de análise na direção de uma interpretação mais precisa de como a função suprimentos (ou compras) atua sobre a estratégia de marcas próprias.

Por fim, ressalta-se que ainda não se esgotaram as indagações que circundam o campo da estratégia de marcas próprias e da gestão de suprimentos, pois ainda são incipientes estudos que relacionam o setor atacadista nas funções que integram cadeia de suprimentos e estratégias de marketing.

\title{
Do own brand strategies influence the supply chain management? Insights from the Brazilian wholesaling sector
}

\begin{abstract}
The evolution of the wholesaling sector in the past few years has made possible that some traditional corporate functions of the supply chain were significantly influenced by its marketing strategies. The literature shows a deep relation between own brand strategies and the activities of supply management. It happens because the development of own brands makes the wholesaler a very careful buyer that aims at selecting and evaluating the suppliers in order to obtain the best performance of the own brand products. In this way, the main objective of this paper is to analyse the impact of the supply management in the own brand strategy in wholesalers, analysing the procedures and criteria used by wholesalers to select and evaluate own brand suppliers. From a multicase study with three wholesalers and two suppliers, all Brazilian companies, it is possible to demonstrate the main characteristics of the own brand suppliers' selection and evaluation process.
\end{abstract}

Keywords: Supply management. Own brand. Wholesale.

\section{Referências bibliográficas}

AAKER, D. A. et al. Pesquisa de marketing. 2 ed. São Paulo: Atlas, 2004. 745 p.

ABAD - Associação Brasileira de Atacadistas e Distribuidores. Dados do setor. Disponível em: <http://www.abad.com.br/ index 2.html>. Acesso em: 1 set. 2006.

ALCÂNTARA, R. L. C. A gestão estratégica dos canais de distribuição: um exame da evolução e do atual estágio do relacionamento entre o atacado de entrega e a indústria. São Paulo, 1997. 194 f. Tese - (Doutorado em Administração), EAESP-FGV.

ALVES, M. R. Logística agroindustrial. In: BATALHA, M. O. et al. Gestão agroindustrial. São Paulo: Atlas, 2001, p. 162-240.
BAILY, P. et al. Compras: Princípios e administração. São Paulo: Atlas, 2000. $471 \mathrm{p}$.

BALlOU, R. H. Decisões de compras e programação de suprimentos. In: __ Gerenciamento da cadeia de suprimentos: planejamento, organização e logística empresarial. 4 ed. Porto Alegre: Bookman, 2001. cap. 11, p. 312-343.

BALTAS, G. A combined segmentation and demand model for store brands. European Journal of Marketing, v. 37, n. 10, p. 1499-1513, 2003.

BATRA, R.; SINHA, I. Consumer-level factors moderating the success of private label brands. Journal of Retailing, v. 76, n. 2, p. 175-191, 2000. 
BERKOWITZ, E. N. et al. Marketing. 6 ed. Rio de Janeiro: LTC, 2003. v. 2, 454 p.

BERMAN, B. Marketing channels. New York: John Wiley \& sons, 1996. $727 \mathrm{p}$.

BLYTHE, J.; ZIMMERMAN, A. Business-to-business marketing management: a global perspective. London: Thomson Learning, 2005. 403 p.

BOWERSOX, D. J.; CLOSS, D. J. Logística empresarial: o processo de integração da cadeia de suprimento. São Paulo: Atlas, 2001.

BOWERSOX, D. J.; COOPER, M. B. Strategic marketing channel management. New York: McGraw-Hill, 1992. 488 p.

BURT, S. The strategic role of retail brands in British grocery retailing. European Journal of Marketing, v. 34, n. 8, p. 875-897, 2000.

CHETOCHINE, G. A derrota das marcas: como evitá-la? São Paulo: Makron Books, 1999. 144 p.

CHURCHILL Jr., G. A.; PETER, J. P. Marketing: criando valor para o cliente. 2 ed. São Paulo: Saraiva, 2000. 768 p.

CONN, C. Innovation in private-label branding. Design Management Review, v. 16, n. 2, p. 55-72, 2005.

COUGHLAN, A. T. et al. Canais de marketing e distribuição. 6 ed. Porto Alegre: Bookman, 2002. 461 p.

CZINKOTA, M. R. et al. Marketing: as melhores práticas. Porto Alegre: Bookman, 2001. 559 p.

DANTAS, S. B. et al. Logística de materiais. Apostila da disciplina: Escola de Administração. Rio de Janeiro: UniverCidade, 2002.

DAVIES, G. Retail brands and the theft of identity. International Journal of Retail \& Distribution Management, v. 26, n. 4, p. 140-146, 1998.

DHAR, S. K. et al. Effective category management depends on the role of the category. Journal of Retailing, v. 77, p. 165-184, 2001.

DHAR, S. K.; HOCH, S. J. Why store brand penetration varies by retailer. Marketing Science, v. 16, n. 3, p. 208-227, 1997.

DUNNE, P.; LUSCH, R. F. Varejo e Atacado. In: CZINKOTA, M. R. et al. Marketing: as melhores práticas. Porto Alegre: Bookman, 2001. 559 p. cap. 11.

GIL, A. C. Como elaborar projetos de pesquisa. 3 ed. São Paulo: Atlas, 1996. 159 p.

HOCH, S. J. How should national brands think about private labels? Sloan Management Review, v. 37, n. 2, p. 89-102, 1996.

HOCH, S. J.; BANERJI, S. When do private labels succeed? Sloan Management Review, v. 34, n. 4, p.57-67, 1993.

KOTLER, P.; KELLER, K. L. Administração de marketing. 12 ed. São Paulo: Pearson Prentice Hall, 2006. 750 p.

LAMBERT, D. M.; COOPER, M. C. Issues in supply chain management. Industrial Marketing Management, v. 29, n. 1, p. $65-83,2000$.

LAMBERT, D. M.; STOCK, J. R.; VANTINE, J. G. Compras. In: Administração estratégica da logística. São Paulo: Vantine Consultoria, 1998. cap. 12.

LUSCH, R. F.; ZIZZO, D.; KENDERDINE, M. Strategic renewal in distribution. Marketing Management, v. 2, n. 2, p. 20-30, 1993.

MARTINS, M. F. Análise da função suprimentos nas empresas de manufatura: o caso das empresas de linha branca. São Carlos, 1999. 196 f. Tese - (Doutorado) Escola de Engenharia de São Carlos, Universidade de São Paulo.

McGOLDRICK, P. J. Retail marketing. London: McGraw-Hill, 1990. 362 p.
McGOLDRICK, P. J. Varejo. In: BAKER, M. J. et al. Administração de marketing. 5 ed. Rio de Janeiro: Campus (Elsevier), 2005. 603 p. cap. 30.

MENTZER, J. T. et al. Defining supply chain management. Journal of Business Logistics, v. 22, n. 2, p. 1-25, 2001.

MORTON, F. S.; ZETTELMEYER, F. The strategic positioning of store brands in retailer-manufacturer negotiations. Review of Industrial Organization, v. 24, n. 2, p. 161-194, 2004.

NEVES, M. F. Um modelo para canais de distribuição no setor de alimentos. São Paulo, 1999. 297 f. Tese - (Doutorado em Administração) - FEA / USP.

OLIVEIRA, G.; MACHADO, E. L. Impactos verticais da concentração do setor varejista brasileiro. São Paulo: EAESP/FGV, 2003.

OLIVEIRA, R. N. A. Marca própria. Rio de Janeiro: Brasport, 2005. $251 \mathrm{p}$.

PÁDUA, E. M. M. Metodologia da pesquisa: abordagem teóricoprática. 2 ed. Campinas: Papirus, 1997. 94 p.

PARENTE, J. Varejo no Brasil: gestão e estratégia. São Paulo: Atlas, 2000. 388 p.

PIATO, E. L. Estratégia de marcas próprias: estudo multicaso no atacado brasileiro. São Carlos, 2006. 257 f. Dissertação (Mestrado em Engenharia de Produção) - Universidade Federal de São Carlos - UFSCar.

PIRES, S. R. I. Gestão da Cadeia de Suprimentos: conceitos, estratégias, práticas e casos - Supply Chain Management. São Paulo: Atlas, 2004.

ROCHA, A.; CHRISTENSEN, C. Marketing: teoria e prática no Brasil. 2 ed. São Paulo: Atlas, 1999. 284 p.

ROSENBRÖIJER, C. J. Industrial brand management: a distributor's perspective in the UK fine-paper industry. Journal of Product \& Brand Management, v. 10, n. 1, p. 7-24, 2001.

SHOCKER, A. D.; SRIVASTAVA, R. K.; RUEKERT, R. W. Challenges and opportunities facing brand management: an introduction to the special issue. Journal of Marketing Research, v. 31, n. 2, p. 149-158, 1994.

SLACK, N. et al. Administração da produção. 2 ed. São Paulo: Atlas, 2002.

SOUZA, M. G.; NEMER, A. Marca \& distribuição: desenvolvendo dominação estratégica e vantagem competitiva no mercado global. São Paulo: Makron Books, 1993. 239 p.

STEINER, R. L. The nature and benefits of national brand/private label competition. Review of Industrial Organization, v. 24, n. 2, p. 105-127, 2004

STERN, L. W.; EL-ANSARY, A. I. Marketing channels. 5 ed. New Jersey: Prentice Hall, 1996.

TAVARES, M. C. A força da marca: como construir e manter marcas fortes. São Paulo: Harbra, 1998. 220 p.

TOILLIER, A. L. Análise do mercado supermercadista de marcas próprias sob a perspectiva do fabricante. Porto Alegre, 2003. 119 f. Dissertação - (Mestrado em Administração), Universidade Federal do Rio Grande do Sul.

TRIVIÑOS, A. N. S. Introdução à pesquisa em ciências sociais: a pesquisa qualitativa em educação. São Paulo: Atlas, 1992. $175 \mathrm{p}$.

Van WEELE, A. J. Purchasing \& supply chain management: analysis, strategy, planning and practice. 4 ed. London: Thomson Learning, 2005. 364 p.

VELOSO, A. R. Processo de introdução de marcas próprias no varejo supermercadista brasileiro: um estudo de caso múltiplo. Porto Alegre, 2004. 155 f. Dissertação - (Mestrado em Administração), Universidade Federal do Rio Grande do Sul. 
VELOUTSOU, C.; GIOULISTANIS, E.; MOUTINHO, L. Own labels choice criteria and perceived characteristics in Greece and Scotland: factors influencing the willingness to buy. The Journal of Product and Brand Management, v. 13, n. 4, p. 228-241, 2004.
WEBSTER Jr., F. E. Understanding the relationships among brands, consumers and resellers. Journal of the Academy of Marketing Science, v. 28, n. 1, p. 17-23, 2000.

YIN, R. K. Estudo de caso: planejamento e métodos. 2 ed. Porto Alegre: Bookman, 2001. 205 p.

\section{Sobre os autores}

\section{Éderson Luiz Piato Andrea Lago da Silva Verônica Angélica Freitas de Paula}

Grupo de Estudos e Pesquisas Agroindustriais, Departamento de Engenharia de Produção, Universidade Federal de São Carlos - UFSCar,

Rodovia Washington Luís, Km 235, CP 676, CEP 13560-970, São Carlos, SP, Brasil, e-mails: ederpiato@dep.ufscar.br; deialago@ufscar.br; vafp@terra.com.br

Agradecimentos: Os autores agradecem à Coordenação de Aperfeiçoamento de Pessoal de Nível Superior (CAPES) e à Fundação de Amparo à Pesquisa do Estado de São Paulo (FAPESP) que financiaram respectivamente a bolsa de mestrado e a pesquisa que deu origem a este artigo. 